\title{
Adipokines, insulin resistance, hepatic steatosis, and necroinflammation in patients with chronic viral hepatitis
}

\author{
Sombat Treeprasertsuk ${ }^{\mathrm{a}}$, Piyawat Komolmita ${ }^{\mathrm{a}}$, Wiriya Tanyaowalak ${ }^{\mathrm{b}}$ \\ ${ }^{a}$ Division of Gastroenterology, Faculty of Medicine, Chulalongkorn University, Bangkok 10330, \\ ${ }^{b}$ Division of Medicine, Pra-pinklao Hospital, Bangkok 10600, Thailand
}

\begin{abstract}
Background: Hypoadiponectinemia and hyperleptinemia, and reductions in the ratio of adiponectin to leptin (A/L ratio) are associated with the development of hepatic necroinflammation in nonalcoholic fatty liver, but the association of the adipokines with hepatic steatosis in chronic viral hepatitis is unclear.

Objective: To investigate the relationship between serum A/L ratio, insulin resistance, degree of hepatic steatosis, and necroinflammation in patients with chronic viral hepatitis.

Methods: We measured serum adiponectin, leptin, and resistin levels, insulin resistance, and analyzed the association between liver histopathology and the level of the adipokines in 44 patients with chronic viral hepatitis before they started treatment.

Results: We found that insulin resistance, leptin, and resistin levels tended to increase in the group with a greater degree of hepatic steatosis and necroinflammation, but that the increase was not significant. The adiponectin/leptin ratio (A/L ratio) in a group with a low degree of hepatic steatosis was significantly higher than it was in the group with a high degree of hepatic steatosis $(3.1 \pm 3.1 \mathrm{vs} 1.2 \pm 0.8 ; P=0.008)$. The $\mathrm{A} / \mathrm{L}$ ratio in a group with low histological activity index (HAI) scores was significantly higher than in the group with high HAI scores ( $3.7 \pm 3.4$ vs $1.1 \pm 1.1 ; P=0.006)$. Abdominal obesity was the only variable that showed a significant association with the HAI score $(P=0.03)$.

Conclusion: The serum A/L ratio in patients with chronic viral hepatitis showed a significant inverse association with their degree of hepatic steatosis and necroinflammation.
\end{abstract}

Keywords: Adiponectin/leptin ratio, chronic viral hepatitis, insulin resistance

Adipokines, such as adiponectin, leptin, and resistin, are released abundantly by adipocytes and stimulate the release of cytokines, such as tumor necrosis factor- $\alpha$, interleukin -6 , and interleukin- 1 from inflammatory cells infiltrating fat. The consequences of these processes are local and generalized inflammation, mediated as a cause of obesity-related vascular disorders that are found in MetS including hypertension, diabetes, atherosclerosis, and insulin resistance. There are many reports related to adipokine hormones, which play an important role in insulin resistance, and are a major cause of pathophysiology in patients with nonalcoholic fatty liver disease (NAFLD). Low adiponectin

Correspondence to: Sombat Treeprasertsuk, MD, PhD, Division of Gastroenterology, Faculty of Medicine, Chulalongkorn University, Bangkok 10330, Thailand. E-mail: battan5410@ yahoo.com concentration is independently associated with the probability of hepatic steatosis in patients with MetS [1-5]. The link between low adiponectin concentration and hepatic steatosis, degree of hepatic necroinflammation and fibrosis, was studied and confirmed in patients with NAFLD. Hypoadiponectinemia and hyperleptinemia or the reduction of adiponectin/leptin ratio (A/L ratio) are associated with alanine aminotransferase elevation and the development of hepatic necroinflammation [6]. In chronic viral hepatitis, which also includes some degree of hepatic steatosis, adipokines may contribute to the mechanisms of progression in necroinflammatory and fibrosis such as found in chronic viral hepatitis $\mathrm{C}$ (CHC). Hepatic steatosis has been described in $31 \%-72 \%$ of $\mathrm{CHC}$ liver biopsies. Hepatic steatosis has been shown to influence disease progression and is known as an independent predictor of a poor treatment response in CHC treatment [4, 7]. A study 
to explore the association between leptin, metabolic factors, and liver histology was conducted in CHC patients, but the results showed that leptin was poorly predictive of severe steatosis [8]. Therefore, the aims of this study were to investigate the relationship between serum $\mathrm{A} / \mathrm{L}$ ratio, insulin sensitivity, hepatic steatosis, and degree of hepatic necroinflammation in patients with chronic viral hepatitis $\mathrm{B}(\mathrm{CHB})$ and CHC.

\section{Patients and methods Patients}

This prospective analytical study was conducted of consecutive patients with $\mathrm{CHB}$ or $\mathrm{CHC}$ who were na ve to treatment and underwent liver biopsy at King Chulalongkorn Memorial Hospital between January 2006 and January 2007. All participants had hepatitis B virus surface antigen (HBsAg) or antibody against hepatitis $\mathrm{C}$ virus (anti-HCV), serum alanine aminotransferase level $\geq 40 \mathrm{U} / \mathrm{L}$, with liver histopathology being compatible with CHB or CHC. Hepatitis B virus DNA(HBV-DNA) being more than 100,000 copies/mL for patients with positive hepatitis $B$ virus e antigen (HBeAg positive) and more than 10,000 copies/mL for those negative for hepatitis B virus e antigen (HBeAg negative) or were positive for hepatitis $\mathrm{C}$ virus RNA (HCV-RNA) were included into these study. None of these patients had any previous treatment of $\mathrm{CHB}$ or $\mathrm{CHC}$. medications that are commonly known to induce hepatic steatosis such as corticosteroid, valproic acid, amiodarone, and tamoxifen; human immunodeficiency virus infection, and other chronic liver diseases. The study was approved by the institutional ethics committee of Chulalongkorn University and each patient gave written informed consent to participate.

\section{Clinical and laboratory assessment}

The following data were collected at the time of liver biopsy: age, sex, body weight, height, waist circumference, hip circumference (waist circumference was measured at a level midway between the lower rib margin and the iliac crest, while hip circumference was measured at the widest level over the greater trochanters), and blood pressure. After an overnight fast of 12 hours, a blood sample was taken to assay the level of adipokines, including adiponectin, leptin, and resistin. The adipokine concentrations were determined on serum, using a specific commercial kit (Human Adiponectin ELISA/ Leptin RIA Kit; Linco Research, St. Charles, MO, USA). Intra- and interassay coefficients of variation for adiponectin were $5.2 \%$ and $9.8 \%$, respectively. Insulin resistance was determined using the homeostasis model assessment (HOMA) method with the following equation:

$$
\text { Insulin resistance }(\text { HOMA-IR })=\frac{\text { Fasting insulin }(\mathrm{mIU} / \mathrm{mL}) \times \text { Fasting glucose }(\mathrm{mmol} / \mathrm{L})}{22.5}
$$

According to the National Cholesterol Education Program Adult Treatment Panel III (NCEP-ATP III) criteria for Asians, the definition of metabolic syndrome (MetS) recommended by the Asia Pacific Working Party on NAFLD in 2006, includes any 3 or more of the following 5 criteria: central obesity, waist circumference $>90 \mathrm{~cm}$ (men), $>80 \mathrm{~cm}$ (women) and/ or body mass index (BMI) $>25 \mathrm{~kg} / \mathrm{m}^{2}$ in either sex; fasting blood triglycerides $\geq 150 \mathrm{mg} / \mathrm{dL}$; low highdensity lipoprotein cholesterol (men $<40$ mg/dL (1.04 $\mathrm{mmol} / \mathrm{L})$, women $<50 \mathrm{mg} / \mathrm{dL}(1.30 \mathrm{mmol} / \mathrm{L})$ ); elevated blood pressure $\geq 130 / 85 \mathrm{mmHg}$; and elevated fasting glucose $\geq 100 \mathrm{mg} / \mathrm{dL}(5.6 \mathrm{mmol} / \mathrm{L})$ or previously diagnosed type 2 diabetes. The following conditions were excluded: diabetes mellitus, body mass index (BMI) $\geq 30 \mathrm{~kg} / \mathrm{m}^{2}$; active alcohol drinking ( $\geq 20$ g or 2 units/day of alcohol in past 6 months); the use of

\section{Liver histopathology}

All of the enrolled patients were admitted for liver biopsy and blood tests. Standard liver biopsy was performed under ultrasound guidance. Liver tissue was evaluated by an experienced gastrointestinal pathologist who was blinded to the adipokine data. The degree of necroinflammatory activity and fibrosis were scored using the histological activity index (HAI), also known as the Knodell score. A low level of necroinflammation was defined by an HAI score $<8$. The degree of steatosis was assessed as the percentage of hepatocytes containing macrovesicular fat droplets according to Brunt's classification [9] and was graded as 0 (no steatosis), 1 ( $<33 \%$ of hepatocytes affected), 2 (33\%-66\% of hepatocytes affected), or 3 ( $>66 \%$ of hepatocytes affected). Significant hepatic steatosis was defined as grade 2 and 3 . Then we 
categorized the patients into 2 groups: "low degree of steatosis group" for grade $0-1$ steatosis and "high degree of steatosis group” for grade 2 or 3 steatosis.

\section{Data analysis}

Baseline descriptive data are expressed as means and standard deviations for continuous variables, and as percentages and frequencies for categorical variables. Differences between groups were assessed using a Student $t$ test for parametric data, and a Mann-Whitney $U$ test for nonparametric data. Proportional data were assessed using a chi-square test.

\section{Results}

Forty-four patients with chronic viral hepatitis were enrolled in this study between January 2006 and January 2007. There were 19 patients who had CHB and 25 patients who had CHC. Among the 19 patients with $\mathrm{CHB}$, there were 9 in the in HBeAg-positive group, 9 in the HBeAg-negative group, and 1 patient with unknown HBeAg status. HBV-DNA was reported to be over 20 million copies/mL in 8 of the 19 patients (42\%). Among the 25 patients with $\mathrm{CHC}$, there were 6 patients with genotype 1, 12 patients with genotype 3 , and the genotypes of the remaining 7 patients were unknown.
The degree of hepatic steatosis was classified into 2 groups being a low and a high degree of steatosis. The proportion of patients with a high degree of hepatic steatosis (grade 2 or 3 ) with CHB was $16 \%$ and $16 \%$ for patients with CHC. Their demographic data and biochemical parameters are shown in Table 1. There was no significant difference between the groups of patients with low and high degree of hepatic steatosis.

There was no patient in this study who met the 3 criteria for a diagnosis of MetS. As shown in Table 2 about $84 \%$ patients had $\leq 1$ criterion of MetS and only 7 patients had 2 of the 3 criteria required for a diagnosis of MetS. Most frequent criteria for MetS found were high blood pressure and abdominal obesity using waist circumference. There was no association between abdominal obesity and the type of chronic viral hepatitis $(P=0.21)$. Moreover, there was no difference in the proportion of criteria for MetS between the groups of patients with high or low degrees of hepatic steatosis $(P=0.98)$.

The degree of liver necroinflammation, which was represented by HAI score, showed no association with the causes of chronic hepatitis $(P=0.15)$. However, there was a significant association between HAI score and abdominal obesity $(P=0.03)$, as shown in Table 3.

Table 1. Patient demographic data, biochemical, and metabolic features of $44 \mathrm{CHB}$ and CHC patients

\begin{tabular}{|c|c|c|c|c|}
\hline Variables & $\begin{array}{l}\text { Overall } \\
(n=44)\end{array}$ & $\begin{array}{l}\text { Low degree of hepatic } \\
\text { steatosis grade } 0-1 \\
\quad(n=37)\end{array}$ & $\begin{array}{l}\text { High degree of hepatic } \\
\text { steatosis grade } 2 \text { or } 3 \\
(n=7)\end{array}$ & $\boldsymbol{P}$ \\
\hline Number of female/total (\%) & $7 / 44(16 \%)$ & 6/37 (16\%) & $1 / 7(14 \%)$ & \\
\hline Age (years old) & $40.9 \pm 10.0$ & $41.6 \pm 10.2$ & $37.7 \pm 9.0$ & 0.35 \\
\hline Body mass index $\left(\mathrm{kg} / \mathrm{m}^{2}\right)$ & $22.8 \pm 2.9$ & $22.8 \pm 2.8$ & $22.8 \pm 3.8$ & 0.98 \\
\hline Waist circumference (cm) & $83.4 \pm 7.6$ & $83.3 \pm 7.3$ & $84.1 \pm 9.6$ & 0.78 \\
\hline Hip circumference (cm) & $94.5 \pm 5.9$ & $94.1 \pm 5.9$ & $96.4 \pm 6.3$ & 0.36 \\
\hline Waist/hip ratio & $0.88 \pm 0.05$ & $0.88 \pm 0.04$ & $0.87 \pm 0.08$ & 0.73 \\
\hline Glucose (mg/dL) & $87.6 \pm 11.4$ & $87.7 \pm 12.1$ & $86.8 \pm 7.2$ & 0.85 \\
\hline Alanine aminotransferase (U/L) & $112.3 \pm 82.0$ & $116.5 \pm 87.6$ & $90.5 \pm 38.2$ & 0.45 \\
\hline Total cholesterol (mg/dL) & $181.7 \pm 41.3$ & $180.5 \pm 37.6$ & $188.6 \pm 60.3$ & 0.64 \\
\hline Triglycerides (mg/dL) & $88.4 \pm 38.4$ & $93.2 \pm 39.3$ & $63.4 \pm 21.2$ & 0.06 \\
\hline High-density lipoprotein cholesterol (mg/dL) & $54.5 \pm 13.4$ & $54.3 \pm 13.0$ & $56.0 \pm 16.5$ & 0.76 \\
\hline Insulin level (mIU/mL) & $6.0 \pm 5.9$ & $6.4 \pm 6.4$ & $3.9 \pm 1.9$ & 0.32 \\
\hline Mean HAI score (range) & $5.9(1-10)$ & $6.0 \pm 2.4$ & $5.4 \pm 1.3$ & 0.59 \\
\hline
\end{tabular}


Table 2. Number of chronic viral hepatitis patients who met metabolic syndrome (MetS) criteria

\begin{tabular}{lccc}
\hline Criteria of MetS (NCEP-ATP III) & Frequency & Percent (\%) \\
\hline Number of criteria & 0 & 13 & 30 \\
& 1 & 24 & 54 \\
& 2 & 7 & 16 \\
\hline
\end{tabular}

Table 3. Association between histological activity index (HAI) score and abdominal obesity

\begin{tabular}{llll}
\hline & \multicolumn{2}{c}{ Abdominal obesity } & Total (\%) \\
\cline { 2 - 3 } & Obese & Non obese & \\
\hline HAI score & & & \\
$<8$ & 4 & 22 & $26(59 \%)$ \\
$\geq 8$ & 8 & 10 & $18(41 \%)$ \\
Total & 12 & 32 & 44 \\
\hline
\end{tabular}

The HOMA-IR, leptin, and resistin level tended to be increased in the group of patients with a high degree of hepatic steatosis and necroinflammation, but this tendency was not significant. The $\mathrm{A} / \mathrm{L}$ ratio in patients from the group with a low degree of steatosis was significantly higher than in patients from the group with a high degree of hepatic steatosis (3.1 \pm 3.1 vs $1.2 \pm 0.8 ; P=0.008$ ) as shown in Table 4. Moreover, the $\mathrm{A} / \mathrm{L}$ ratio in patients from the group with low HAI scores was significantly higher than in the group with high HAI scores (3.7 \pm 3.4 vs $1.1 \pm 1.1 ; P=0.006)$ as shown in Table 5.

Table 4. Baseline homeostasis model assessment insulin resistance and adipokine levels in 44 patients with chronic viral hepatitis divided according to their degree of hepatic steatosis

\begin{tabular}{lccc}
\hline Variables & $\begin{array}{c}\text { Low degree of hepatic } \\
\text { steatosis grade } \mathbf{0 - 1} \\
(\mathbf{n}=\mathbf{3 7})\end{array}$ & $\begin{array}{c}\text { High degree of hepatic } \\
\text { steatosis grade } \mathbf{2} \text { or } \mathbf{3} \\
\mathbf{( n = 7 )}\end{array}$ & $\begin{array}{c}\boldsymbol{P} \\
\text { (n) }\end{array}$ \\
\hline Homeostasis model assessment insulin resistance & $1.5 \pm 1.6$ & $7.5 \pm 2.2$ & 0.73 \\
Leptin $(\mathrm{ng} / \mathrm{mL})$ & $6.5 \pm 6.4$ & $37.7 \pm 9.0$ & 0.35 \\
Adiponectin $(\mu \mathrm{gg} / \mathrm{mL})$ & $8.9 \pm 4.1$ & $9.3 \pm 7.0$ & 0.83 \\
Resistin $(\mathrm{ng} / \mathrm{mL})$ & $26.7 \pm 16.3$ & $32.3 \pm 9.9$ & 0.46 \\
A/L ratio* & $3.1 \pm 3.1$ & $1.2 \pm 0.8$ & $0.008^{*}$ \\
\hline
\end{tabular}

$* P<0.05$

Table 5. Baseline homeostasis model assessment insulin resistance and adipokine level of 44 patients with chronic viral hepatitis divided according to their histological activity index (HAI) score

\begin{tabular}{llll}
\hline Variables & $\begin{array}{l}\text { HAI }<\mathbf{8} \\
(\mathbf{n}=\mathbf{2 6})\end{array}$ & $\begin{array}{l}\text { HAI } \geq \mathbf{8} \\
(\mathbf{n}=\mathbf{1 8})\end{array}$ & $\boldsymbol{P}$ \\
\hline Homeostasis model assessment insulin resistance & $1.1 \pm 1.5$ & $2.1 \pm 1.3$ & 0.11 \\
Leptin $(\mathrm{ng} / \mathrm{mL})$ & $5.5 \pm 4.8$ & $10.6 \pm 9.7$ & 0.07 \\
Adiponectin $(\mu \mathrm{g} / \mathrm{mL})$ & $9.5 \pm 4.4$ & $6.9 \pm 3.5$ & 0.17 \\
Resistin $(\mathrm{ng} / \mathrm{mL})$ & $29.1 \pm 15.8$ & $27.8 \pm 14.6$ & 0.85 \\
A/L ratio* & $3.7 \pm 3.4$ & $1.1 \pm 1.1$ & $0.006^{*}$ \\
\hline
\end{tabular}

$* P<0.05$ 


\section{Discussion}

We measured the serum levels of adipokine hormones in a consecutive cohort of 44 patients with CHB and CHC, none of whom met the criteria for a diagnosis of MetS. Patients with diabetes mellitus, a BMI $\geq 30 \mathrm{~kg} / \mathrm{m}^{2}$, and active alcohol drinking were excluded to eliminate confounding factors in the evaluation of serum adipokine levels. The degree of hepatic steatosis and necroinflammation was reviewed intensively by liver pathologists. The present study demonstrates that the severity of hepatic steatosis and necroinflammation is not associated with insulin resistance or the level of any single adipokine. However, the A/L ratio appears a strong indicator with which to assess the severity of hepatic steatosis and level of necroinflammation. The $\mathrm{A} / \mathrm{L}$ ratio had a negative association with the degree of both steatosis and necroinflammation. These findings were independent of age, sex, viral type, BMI, and adipokine level. Thus, the $\mathrm{A} / \mathrm{L}$ ratio may be used as a sensitive test to detect a higher severity of liver necroinflammation in nonobese patients with $\mathrm{CHB}$ or CHC. We also showed that abdominal obesity using waist circumference is a good clinical criterion for assessing the association between HAI score and abdominal obesity, and waist circumference showed a significant positive association with HAI score.

In addition, we confirmed the presence of significant hepatic steatosis in both CHB and CHC, which was found in only about $16 \%$, being quite low compared with that reported in other studies, which ranged between $31 \%$ and $72 \%$ [10-12]. Most of those studies showed a high frequency of hepatic steatosis was found predominantly in CHC patients with genotype non-3. Those CHC patients frequently had a MetS, such as high BMI. Therefore, the population selection in previous studies is quite different from that in the present study in which none of the patients met the required criteria for a diagnosis of MetS (nonobese patients). However, a limitation of our study was the low number of patients, especially in the group with a higher degree of hepatic steatosis and necroinflammation.

The association of inflammatory process in liver histopathology with steatosis and adipokines was clearly suggested in patients with nonalcoholic fatty liver disease (NAFLD), but it was inconclusive in chronic viral hepatitis [13-17]. Obesity itself may contribute to disease progression in $\mathrm{CHC}$ through inflammation and steatosis, and affect the response to treatment. Sanyal et al. showed the importance of the presence of fatty liver and disease progression in patients with HCV. They showed that fatty liver was strongly associated with features of MetS and may be a risk factor for advanced fibrosis. However, the BMI of their patients was $>30 \mathrm{~kg} / \mathrm{m}^{2}$, so obesity may be involved in their disease progression [18-20]. The degree of advanced liver fibrosis in such patients is related to body weight, the presence of diabetes, and the presence and degree of cytological ballooning. The endocrine function of adipose tissue, which produces adipokines, could partially explain these complex associations. The source of adipokines from the obese patients (high BMI) and from visceral fat are being studied to determine their relationship with the severity of liver fibrosis [21-26].

The present study, which consisted mainly of nonobese patients $\left(\mathrm{BMI}<25 \mathrm{~kg} / \mathrm{m}^{2}\right)$ also confirms that there was no patient showing a high grade of severe liver necroinflammation and fibrosis. However, other mechanisms and associated factors may affect the severity of liver disease including the quantitative viral infection load, viral hepatitis $C$ genotype, and hostmediated insulin resistance [27, 28]. All of these factors may enhance the process of fibrosis, alter immune responses, and decrease the response rate to interferon-based therapy. A larger number of chronic viral hepatitis patients is needed to further elucidate these associations [29-33].

In conclusion, the serum $\mathrm{A} / \mathrm{L}$ ratio showed a significant negative association with the degree of hepatic steatosis and degree of hepatic necroinflammation (HAI score) in patients with chronic viral hepatitis. Abdominal obesity was the only single clinical criterion that showed a significant association with the HAI score, and may be used in clinical practice to screen for a high risk of liver disease progression.

\section{Acknowledgments}

The authors thank Dr. Rungsunn Tungtrongchitr, Division of Tropical Nutrition and Food Sciences, Mahidol University, Bangkok, Thailand for helping to assay the adiponectin, leptin, and resistin. Sombat Treeprasertsuk was supported by a medical research grant from the Faculty of Medicine, Chulalongkorn University, and King Chulalongkorn Memorial Hospital, Thai Red Cross Society, Bangkok, Thailand 10330; Ratchadapiseksompotch Fund, Grant number PP5/49. No authors have any conflict of interest to report. 


\section{References}

1. Sanyal AJ. Review article: non-alcoholic fatty liver disease and hepatitis C-risk factors and clinical implications. Aliment Pharmacol Ther. 2005; 22(Suppl 2):48-51.

2. Marra F, Aleffi S, Bertolani C, Petrai I, Vizzutti F. Review article: the pathogenesis of fibrosis in nonalcoholic steatohepatitis. Aliment Pharmacol Ther. 2005; 22(Suppl 2):44-7.

3. Trombetta M, Spiazzi G, Zoppini G, Muggeo M. Review article: type 2 diabetes and chronic liver disease in the Verona diabetes study. Aliment Pharmacol Ther. 2005; 22(Suppl 2):24-7.

4. Lonardo A, Adinolfi LE, Loria P, Carulli N, Ruggiero G, Day CP. Steatosis and hepatitis C virus: mechanisms and significance for hepatic and extrahepatic disease. Gastroenterology. 2004; 126:586-97.

5. Clouston AD, Jonsson JR, Powell EE. Steatosis as a cofactor in other liver diseases: hepatitis $\mathrm{C}$ virus, alcohol, hemochromatosis, and others. Clin Liver Dis. 2007; 11:173-89.

6. Yokoyama H, Hirose H, Ohgo H, Saito I. Inverse association between serum adiponectin level and transaminase activities in Japanese male workers. J Hepatol. 2004; 41:19-24.

7. Antunez I, Aponte N, Fernandez-Carbia A, Rodriguez-Perez F, Toro DH. Steatosis as a predictive factor for treatment response in patients with chronic hepatitis C. P R Health Sci J. 2004; 23:57-60.

8. Myers RP, Messous D, Poynard T, Imbert-Bismut F. Association between leptin, metabolic factors and liver histology in patients with chronic hepatitis C. Can J Gastroenterol. 2007; 21:289-94.

9. Brunt EM, Janney CG, Di Bisceglie AM, Neuschwander-Tetri BA, Bacon BR. Nonalcoholic steatohepatitis: a proposal for grading and staging the histological lesions. Am J Gastroenterol. 1999; 94: 2467-74.

10. Hu KQ, Kyulo NL, Esrailian E, Thompson K, Chase R, Hillebrand DJ, Runyon BA. Overweight and obesity, hepatic steatosis, and progression of chronic hepatitis C: a retrospective study on a large cohort of patients in the United States. J Hepatol. 2004; 40: 147-54.

11. Adinolfi LE, Durante-Mangoni E, Zampino R, Ruggiero G. Review article: hepatitis $\mathrm{C}$ virus-associated steatosis-pathogenic mechanisms and clinical implications. Aliment Pharmacol Ther. 2005; 22(Suppl 2):52-5.

12. Harrison SA. Steatosis and chronic hepatitis C infection: mechanisms and significance. Clin Gastroenterol Hepatol. 2005; 3:S92-6.

13. Guidi M, Muratori P, Granito A, Muratori L, Lenzi M, Bianchi FB. Steatosis in chronic hepatitis C. Gut. 2006; 55:1047-8.

14. Matos CA, Perez RM, Pacheco MS, FigueiredoMendes CG, Lopes-Neto E, Oliveira EB, et al. Steatosis in chronic hepatitis $\mathrm{C}$ : relationship to the virus and host risk factors. J Gastroenterol Hepatol. 2006; 21: 1236-9.

15. Asselah T, Rubbia-Brandt L, Marcellin P, Negro F. Steatosis in chronic hepatitis C: why does it really matter? Gut. 2006; 55:123-30.

16. Szanto P, Grigorescu M, Dumitru I, Serban A. Steatosis in hepatitis $C$ virus infection. Response to anti-viral therapy. J Gastrointestin Liver Dis. 2006; 15:117-24.

17. Zein NN, Poterucha JJ. Steatosis in hepatitis C: the missing link to metabolic abnormalities? Am J Gastroenterol. 2006; 101:2616-8.

18. Asselah T, Boyer N, Guimont MC, Cazals-Hatem D, Tubach F, Nahon K, et al. Liver fibrosis is not associated with steatosis but with necroinflammation in French patients with chronic hepatitis C. Gut. 2003; 52:1638-43.

19. Testino G, Sumberaz A. Liver steatosis and antiviral therapy in chronic hepatitis C. Liver Int. 2007; 27:287.

20. Sanyal AJ, Contos MJ, Sterling RK, Luketic VA, Shiffman ML, Stravitz RT, et al. Nonalcoholic fatty liver disease in patients with hepatitis $\mathrm{C}$ is associated with features of the metabolic syndrome. Am J Gastroenterol. 2003; 98:2064-71.

21. Gordon A, McLean CA, Pedersen JS, Bailey MJ, Roberts SK. Hepatic steatosis in chronic hepatitis B and $\mathrm{C}$ : predictors, distribution and effect on fibrosis. J Hepatol. 2005; 43:38-44.

22. Romero-G mez M. Hepatitis $C$ and insulin resistance: steatosis, fibrosis and non-response. Rev Esp Enferm Dig. 2006; 98:605-15.

23. Ramesh S, Sanyal AJ. Hepatitis C and nonalcoholic fatty liver disease. Semin Liver Dis. 2004; 24:399-413.

24. Bjornsson E, Angulo P. Hepatitis C and steatosis. Arch Med Res. 2007; 38:621-7.

25. Lonardo A, Loria P, Adinolfi LE, Carulli N, Ruggiero G. Hepatitis $C$ and steatosis: a reappraisal. J Viral Hepat. 2006; 13:73-80.

26. Koike K. Hepatitis $\mathrm{C}$ as a metabolic disease: Implication for the pathogenesis of NASH. Hepatol Res. 2005; 33: 145-50.

27. Goodman ZD. Grading and staging systems for inflammation and fibrosis in chronic liver diseases. $\mathrm{J}$ 
Hepatol. 2007; 47:598-607.

28. Durante-Mangoni E, Zampino R, Marrone A, Tripodi MF, Rinaldi L, Restivo L, et al. Hepatic steatosis and insulin resistance are associated with serum imbalance of adiponectin/tumour necrosis factor- $\alpha$ in chronic hepatitis C patients. Aliment Pharmacol Ther. 2006; 24:1349-57.

29. Hu KQ, Currie SL, Shen H, Cheung RC, Ho SB, Bini EJ, et al. Clinical implications of hepatic steatosis in patients with chronic hepatitis C: a multicenter study of U.S. veterans. Dig Dis Sci. 2007; 52:570-8.

30. Sayed HA, El Ayyat A, El Dusoki H, Zoheiry M, Mohamed S, Hassan M, et al. A cross sectional study of hepatitis B, C, some trace elements, heavy metals, aflatoxin B1 and schistosomiasis in a rural population,
Egypt. J Egypt Public Health Assoc. 2005; 80:355-88.

31. Bedossa P, Moucari R, Chelbi E, Asselah T, Paradis V, Vidaud M, et al. Evidence for a role of nonalcoholic steatohepatitis in hepatitis C: a prospective study. Hepatology. 2007; 46:380-7.

32. Oben JA, Paulon E. Fatty liver in chronic hepatitis C infection: unravelling the mechanisms. Gut. 2007; 56: 1186-8.

33. Anty R, Gelsi E, Giudicelli J, Marine-Barjoan E, Gual $\mathrm{P}$, Benzaken S, et al. Glucose intolerance and hypoadiponectinemia are already present in lean patients with chronic hepatitis C infected with genotype non-3 viruses. Eur J Gastroenterol Hepatol. 2007; 19:671-7. 